\title{
2020 Update to Spinal Muscular Atrophy Management in Saudi Arabia
}

\author{
Fahad A. Bashiri ${ }^{1,2 * t}$, Mohamad-Hani Temsah ${ }^{1,3+}$, Khalid Hundallah ${ }^{4 t}$, Fahad Alsohime ${ }^{1,3+}$ \\ and Yazed AlRuthia ${ }^{5,6 t}$ \\ ${ }^{1}$ College of Medicine, King Saud University, Riyadh, Saudi Arabia, ${ }^{2}$ Division of Pediatric Neurology, Department of Pediatrics, \\ King Saud University Medical City, Riyadh, Saudi Arabia, ${ }^{3}$ Pediatric Intensive Care Unit, Pediatric Department, King Saud \\ University Medical City, Riyadh, Saudi Arabia, ${ }^{4}$ Division of Neurology, Department of Pediatrics, Prince Sultan Military Medical \\ City, Riyadh, Saudi Arabia, ${ }^{5}$ Department of Clinical Pharmacy, College of Pharmacy, King Saud University, Riyadh, Saudi \\ Arabia, ${ }^{6}$ Pharmacoeconomics Research Unit, College of Pharmacy, King Saud University, Riyadh, Saudi Arabia
}

Novel therapeutic strategies have shown some promise in treating spinal muscular atrophy (SMA). However, the outcomes and acceptance of these new strategies are yet to be explored. We aimed to investigate physicians' opinions and perceptions toward management strategies of SMA across Saudi Arabia. This is a cross-sectional survey using a self-administered, structured questionnaire sent to physicians who care for SMA patients during the Saudi Pediatric Neurology Society annual conference. A total of 72 clinicians of different neurological subspecialties were included. $48.6 \%$ prescribed nusinersen to their patients, with 39\% of them having patients started on nusinersen. Though, $8.3 \%$ prescribed onasemnogene abeparvovec for 1-3 patients, while none of their patients started on the treatment. $64.3 \%$ stated that the only treatment available for SMA in their settings is supportive care. Around $69.4 \%$ described having a moderate to high knowledge on SMA gene therapy, and $79.2 \%$ would recommend it. $48.6 \%$ confirmed they would prescribe gene therapy at the age of 6 months, and $78.3 \%$ would prescribe it for type-I SMA. Pediatric neurologists are receptive to novel and innovative therapies for SMA in Saudi Arabia. However, the high treatment acquisition cost, strict regulations, logistical issues, and budget constraints delay their adoption and implementation.

Keywords: spinal muscular atrophy, gene therapy, nusinersen, onasemnogene abeparvovec, risdiplam, Saudi Arabia

\section{INTRODUCTION}

Spinal muscular atrophy (SMA) is a major autosomal recessive neuromuscular disorder (1). SMA causes motor neuron degeneration in the brain stem and spinal cord, leading to progressive muscle weakness and atrophy (2). Although it is rare, with an estimated incidence rate of 4-10 per 100,000 newborns (3-7), it has the highest mortality rate among affected children compared to other genetic diseases (8).

The SMA pathophysiology is believed to be due to mutations in the survival motor neuron 1 (SMN1) gene (9), which most commonly lead to deletions, in turn causing a deficiency of SMN (10). Low levels of full-length functioning SMN $(\sim 10 \%)$ can partly compensate for SMN1 deficiency (11). All SMA patients have at least one copy of SMN2 (12). They are categorized into SMA type 1-4 (SMA1-SMA4), depending on the age at which the disease started and their motor activity (13). In addition, the number of SMN2 copies is inversely related to the severity of the disease phenotype (14). The frequency of the carrier that causes SMN1 mutations ranges from 1 in 90 to 1 in 47 (5-7). 
The standard of care in SMA is mainly supportive and consists of nutritional and respiratory support, as needed, in addition to management of muscle weakness complications (13, 15-17). There have been many recent developments in the field of SMA treatment (18). Nusinersen (Spinraza $\left.{ }^{\circledR}\right)$, onasemnogene abeparvovec $\left(\right.$ Zolgensma $\left.^{\circledR}\right)$, and risdiplam (Evrysdi $\left.{ }^{\circledR}\right)$ are three innovative disease-modifying drugs approved by multiple regulatory bodies, such as the US Food and Drug Administration (USFDA) and the European Medicines Agency (EMA).

SMA patients are deficient in SMN. Nusinersen is a synthetic antisense oligonucleotide that promotes exon 7 inclusion to promote increased SMN production. Nusinersen was approved by the USFDA in December 2016 to manage both pediatric and adult SMA patients (19). It also received marketing authorization approvals in Europe, Japan, Brazil, Canada, and Australia (20).

Another approach to treating SMA is gene replacement of the mutated SMN1 with normal SMN1. Onasemnogene abeparvovec is an adeno-associated viral vector-based gene therapy drug that replaces the function of the missing or non-functioning SMN1 gene into the patient's cells. It is a once-only treatment given by an intravenous infusion over $60 \mathrm{~min}$. In May 2019, it became the first gene therapy drug for SMA to be approved by the USFDA. Onasemnogene abeparvovec is indicated for the treatment of children $<2$ years old who have bi-allelic SMN1 mutations (21). In May 2020, the European Commission (EC) granted a conditional drug approval (22).

Risdiplam was recently approved by the USFDA and is indicated for the treatment of children aged 2 months or more (23). It is a small-molecule SMN2-splicing modifier. It is orally administered, and it reaches the central nervous system as well as peripheral organs, increasing the production of full-length SMN mRNA $(24,25)$.

One of the "problems of medical care for SMA patients" is that the decision-making regarding SMA management in pediatric patients largely depends on the treating neurologists' and institutions' experiences or small-scale experimental and/or observational studies (15). Despite emerging evidence of the safety and efficacy of the newly approved SMA therapies (26), their acceptance among neurologists in Saudi Arabia is still unclear. This study explored the perceptions and attitudes of SMA-treating neurologists and other specialties toward the use of novel and innovative treatment options for SMA management in Saudi Arabia.

\section{SUBJECTS AND METHODS}

\section{Study Design}

This online, questionnaire-based, cross-sectional study was conducted between February 27 and 29, 2020, among licensed neurologists who attended the annual national Saudi Pediatric Neurology Society Conference. The inclusion criterion was neurologists who provided care for SMA patients, who consented to participate in the survey, and who filled out the questionnaire. A panel of experts in the field of neurology analyzed the questionnaire for its content, and adjustments were made based on feedback from five academic experts. A total of 72 neurologists filled out the questionnaire, and their responses were considered for analysis.

\section{Data Collection}

The questionnaire comprised 25 items including questions on the respondents' sociodemographic and professional characteristics, patient demographic data, current SMA management plans, and perceived obstacles to the adoption and use of new treatment options for SMA management in Saudi Arabia. In addition, the respondents were asked about their awareness and attitude toward gene therapy for SMA management.

\section{Ethical Considerations}

The study was approved by the institutional review board of the College of Medicine, King Saud University (E183539). All information about the participating neurologists was kept confidential.

\section{Statistical Analysis}

We used means and standard deviations to describe continuous variables and frequencies and percentages to describe categorical variables. We performed the Kolmogorov-Smirnov and Levene's tests to assess normality and homogeneity assumptions, respectively, of continuous variables. All statistical analyses were conducted using SPSS ${ }^{\circledR}$ Statistics (IBM Corporation, Armonk, NY, USA).

\section{RESULTS}

\section{General Characteristics of Respondents}

A total of 72 neurologists filled out the questionnaire. Of the 72 respondents, 43 (59.7\%) were males, $63.9 \%$ were consultants, and $63.9 \%$ specialized in pediatric neurology. The years of experience varied, with $45.8 \%$ having $1-5$ years of experience, with the mean being $8.4(6.9)$ years. In addition, $65.3 \%$ of the respondents worked in tertiary care hospitals. Table 1 lists Respondents' sociodemographic and professional characteristics.

The respondents were asked a set of questions to describe their experience with SMA patients. More than half of the respondents $(54.2 \%)$ saw $<5$ SMA patients per year.

The respondents were also asked about three SMA treatments: nusinersen (Spinraza $\left.{ }^{\circledR}\right)$, onasemnogene abeparvovec (Zolgensma $\left.{ }^{\circledR}\right)$, and risdiplam (Evrysdi $\left.{ }^{\circledR}\right)$. Thirty five $(48.6 \%)$ of the respondents prescribed nusinersen, with 39\% having their patients started on nusinersen, while $\sim 8.3 \%$ prescribed onasemnogene abeparvovec to 1-3 patients, none of whom were taking.

In addition, the respondents were asked about the main obstacles to obtaining these three drugs. The most common reason reported was internal hospital logistics (47.1\%), followed by logistical issues outside the hospital (44.3\%). In addition, $40.3 \%$ of the respondents said that the new medications changed the SMA patients' hospital code. With regard to current treatment options, $\sim 64.3 \%$ of the respondents said that full supportive care is the only treatment option in their hospitals, while $31.4 \%$ reported that palliative care, do-not-resuscitate, and 
TABLE 1 | Responders' sociodemographic and professional characteristics.

\begin{tabular}{lcc}
\hline Characteristics & Frequency $(\boldsymbol{N})$ & Percentage (\%) \\
\hline Sex & 43 & 59.7 \\
$\quad$ Male & 29 & 40.3 \\
$\quad$ Female & & \\
Clinical role & 46 & 63.9 \\
$\quad$ Consultant & 10 & 13.9 \\
Specialist & 16 & 22.2 \\
Resident & & \\
Main field of practice & 46 & 63.9 \\
Pediatric neurology & 5 & 6.9 \\
Adult neurology & 14 & 19.4 \\
Pediatric intensive care & 4 & 5.6 \\
Pediatrics & 3 & 4.2 \\
$\quad$ Genetics & & \\
Experience years categorized & 33 & 45.8 \\
1-5 years & 19 & 26.4 \\
6-10 years & 20 & 27.8 \\
$\quad \geq 11$ years & & 65.3 \\
Working Healthcare facility type & 47 & 31.9 \\
Tertiary hospital & 23 & 2.8 \\
Secondary hospital & 2 & \\
Primary health care & & \\
\hline
\end{tabular}

no endotracheal intubation are the current therapies in their hospitals (Table 2).

\section{Knowledge and Attitude Toward Gene Therapy for SMA Treatment}

The respondents were asked about their knowledge of and attitude toward gene therapy and its use to treat SMA. About $69.4 \%$ of the respondents described their knowledge of gene therapy for SMA as moderate to high, and $79.2 \%$ said that they would recommend gene therapy for SMA in their area, $48.6 \%$ said that they would prescribe gene therapy for SMA patients as young as 6 months, and $78.3 \%$ said that they would prescribe it for Type-I SMA.

The respondents were also asked about the main obstacles to not using gene therapy for SMA. About $73.9 \%$ of the respondents said that the major obstacle was the high cost of medication, while $55.1 \%$ said it was the lack of expertise with novel, innovative therapies.

With regard to the hospitals' preparedness to use gene therapy for SMA, $41.7 \%$ of the respondents said that their hospitals were not prepared for this type of treatment, while only $8.3 \%$ found their hospitals entirely prepared for initiating gene therapy once it becomes available (Table 3).

\section{Clinical Judgment of Respondents on Different SMA Case Scenarios}

The respondents were given two different case scenarios of SMA patients and were asked about their clinical decision in each scenario. The first scenario was of an infant who did not
TABLE 2 | Practices and experience of physicians with SMA patients.

\begin{tabular}{lcc}
\hline Practices and experience & Frequency $(\boldsymbol{N})$ & Percentage (\%) \\
\hline How many cases of SMA do you treat per year? & 39 & 54.2 \\
$>5$ & 21 & 29.2 \\
$5-10$ cases per year & 3 & 4.2 \\
more than 10 per year & 9 & 12.5 \\
I do not treat any SMA patient currently & 37 & \\
For how many patients did you prescribe nusinersen? & 51.4 \\
None & 13 & 18.1 \\
1-3 patients & 14 & 19.4 \\
4-6 patients & 44 & \\
How many of these patients did they start on nusinersen? & 61.1 \\
None & 18 & 25 \\
1-3 patients & 6 & 8.3 \\
4-6 patients & 4 & 5.6 \\
$\geq 7$ patients
\end{tabular}

For how many patients did you prescribe onasemnogene abeparvovec?

$\begin{array}{lcc}\text { None } & 66 & 91.7 \\ 1-3 \text { patients } & 4 & 5.6 \\ 4-6 \text { patients } & 2 & 2.8\end{array}$

How many of these patients did they start on onasemnogene abeparvovec?

None $\quad 72 \quad 100$

What were the main obstacles you had in obtaining these SMA treatments?

$\begin{array}{lcc}\text { Hospital internal/Related reasons } & 33 & 47.1 \\ \text { Logistics reasons outside my hospital } & 31 & 44.3 \\ \text { Saudi FDA approval } & 8 & 11.4 \\ \text { Financial/cost } & 39 & 55.7 \\ \text { Family-related obstacles } & 6 & 8.6 \\ \text { Other reasons } & 10 & 7.9\end{array}$

Did the new treatments (like nusinersen or gene therapy) change your hospital code status for SMA patients?

$\begin{array}{lll}\text { No } & 43 & 59.7 \\ Y 0 s & 29 & 40.3\end{array}$

In your hospital, what are the current treatment options for SMA?

$\begin{array}{lcc}\text { Full supportive care } & 45 & 64.3 \\ \text { Non-invasive ventilation } & 21 & 30 \\ \text { Tracheostomy and home ventilation } & 20 & 28.6 \\ \text { Palliative care, do-not-resuscitate, and } & 22 & 31.4 \\ \text { no endotracheal intubation } & & 7.1 \\ \text { Others } & 5 & \end{array}$

SMA, spinal muscular atrophy.

require respiratory support, and the second scenario was of an infant who had respiratory failure and required $12 \mathrm{~h}$ intubation. Onasemnogene abeparvovec was the selected treatment option in (55.6 and $33.3 \%$ for the two scenarios, respectively); $~ 50 \%$ of the respondents said that they would prescribe onasemnogene abeparvovec because of its efficiency.

In addition, more than $50 \%$ of the respondents agreed to using endotracheal intubation for acute exacerbation for SMA patients (51.4\%) and to chronic home ventilation for SMA patients (58.3\%). On the contrary, $50 \%$ of the respondents were against 
TABLE 3 | Knowledge and attitude toward gene therapy for SMA.

$\begin{array}{lcc}\text { Knowledge and attitude toward gene } & \text { Frequency } & \text { Percentage } \\ \text { therapy for SMA } & \text { (N) } & \text { (\%) }\end{array}$

Describe your current knowledge of gene therapy and its use in treating neuromuscular diseases, such as SMA?

$\begin{array}{lcc}\text { Very low } & 6 & 8.3 \\ \text { Low } & 16 & 22.2 \\ \text { Moderate } & 34 & 47.2 \\ \text { High } & 14 & 19.4 \\ \text { Very high } & 2 & 2.8\end{array}$

Would you recommend gene therapy for treating SMA disease in your region?

$\begin{array}{lll}\text { No } & 15 & 20.8 \\ \text { Yes } & 57 & 79.2\end{array}$

In your opinion, what would be the main obstacle(s) for not using gene therapy for SMA patients?

$\begin{array}{lcc}\text { Lack of expertise in using gene therapy } & 38 & 55.1 \\ \text { since it is new } & 5 & 7.2 \\ \text { Other available treatment } & 51 & 73.9 \\ \text { Price/cost of treatment } & 10 & 14.5 \\ \text { Low efficacy } & 2 & 2.9 \\ \text { Side effects } & 7 & 10.1\end{array}$

If you are likely to prescribe gene therapy for SMA patients, what would be the recommended age for treating the patient?

$\begin{array}{lcc}\text { Below } 2 \text { years } & 23 & 31.9 \\ \text { Below 1.5 years } & 4 & 5.6 \\ \text { Below 1 year } & 10 & 13.9 \\ \text { Below } 6 \text { months } & 35 & 48.6\end{array}$

If you are likely to suggest gene therapy for SMA patients, what would be the recommended type of SMA?

$\begin{array}{lll}\text { SMA Type-I } & 54 & 78.3 \\ \text { SMA Type-II } & 38 & 55.1 \\ \text { SMA Type-III } & 25 & 36.2\end{array}$

How prepared is your hospital in terms of Multidisciplinary teams to treat patients with gene therapies such as gene therapy for SMA?

$\begin{array}{lcc}\text { Not at all prepared } & 30 & 41.7 \\ \text { Just starting to prepare } & 14 & 19.4 \\ \text { Making good progress with the preparation } & 14 & 19.4 \\ \text { Very nearly prepared } & 8 & 11.1 \\ \text { Completely prepared } & 6 & 8.3\end{array}$

SMA, spinal muscular atrophy.

chronically ventilating SMA patients in hospitals. Table 4 lists all responses.

\section{DISCUSSION}

This study evaluated the level of acceptance and knowledge of the novel, innovative therapies used for SMA management among a sample of clinicians involved in the care of pediatric SMA patients in Saudi Arabia. Several studies have explored the best approaches to SMA management to improve the patients' and their families' quality of life $(15,27-29)$.
TABLE 4 | Responses of the respondents toward the two case scenarios.

$$
\begin{aligned}
& \text { Responses toward the two case scenarios } \begin{array}{c}
\text { Frequency } \\
\text { Percentage }
\end{array} \\
& \text { (N) }
\end{aligned}
$$

Scenario-1: A hypotonic 3-month-old infant was admitted to your hospital with a respiratory failure diagnosis secondary to

hypoventilation. Genetic testing confirmed SMA. Patient is on room air, with no respiratory support. If all the following treatments are available at your hospital: Which type of treatment would you give this infant?

$\begin{array}{lll}\text { Onasemnogene abeparvovec } & 40 & 55.6\end{array}$

Nusinersen

Risdiplam (once available)

$18 \quad 25$

Other supportive treatments

$6 \quad 8.3$

Neither (no SMA modifying medication) $\quad 4.6$

What is the reason(s) for your choice of therapy in the above question?

The efficiency of this treatment $33 \quad 50$

$\begin{array}{lll}\text { Availability of the treatment } & 16 & 24.2\end{array}$

Other reasons

Neurology team expertise

Price/costs of treatment

Family request

$14 \quad 21.2$

$12 \quad 18.2$

$9 \quad 13.6$

$2 \quad 3$

Scenario-2: A hypotonic 6-month-old infant was admitted to your hospital with a respiratory failure diagnosis secondary to hypoventilation. Genetic testing proved the infant has SMA. The patient has been intubated $12 \mathrm{~h}$ ago. If all the following treatments are available in your hospital, would you give this infant this type of treatment?

$\begin{array}{lll}\text { Onasemnogene abeparvovec } & 24 & 33.3\end{array}$

Neither (no SMA modifying medication) $\quad 21 \quad 29.2$

$\begin{array}{lll}\text { Nusinersen } & 16 & 22.2\end{array}$

$\begin{array}{lll}\text { Risdiplam (once available) } & 9 & 12.5\end{array}$

$\begin{array}{lll}\text { Other supportive treatments } & 2 & 2.8\end{array}$

What is the reason for your choice of therapy in the above question?

$\begin{array}{lll}\text { The efficiency of this treatment } & 30 & 47.6\end{array}$

$\begin{array}{lll}\text { Neurology team expertise } & 16 & 25.4\end{array}$

$\begin{array}{lrr}\text { Availability of the treatment } & 12 & 19\end{array}$

$\begin{array}{lll}\text { Price/costs of treatment } & 9 & 14.3\end{array}$

$\begin{array}{lll}\text { Other reasons } & 9 & 14.3\end{array}$

Family request $\quad 2 \quad 3.2$

What is your opinion about the following statement: "in acute exacerbation, endotracheal intubation is acceptable for SMA patients"

$\begin{array}{lcc}\text { Agree } & 37 & 51.4 \\ \text { Neither agree or disagree } & 17 & 23.6 \\ \text { Disagree } & 18 & 25\end{array}$

What is your opinion about the following statement: "chronic home ventilation is acceptable for SMA patients"

$\begin{array}{lcc}\text { Agree } & 42 & 58.3 \\ \text { Neither agree nor disagree } & 11 & 15.3 \\ \text { Disagree } & 19 & 26.4\end{array}$

Do you have chronically ventilated SMA patients in your hospital? 31 No $\quad 36 \quad 50$

I do not know/Not sure $\quad 5.9$

SMA, spinal muscular atrophy.

After decades of poor prognosis of SMA, the USFDA recently approved gene therapy for SMA treatment (8, 19-21, 23, 30-33). The new SMA modifying treatments have significantly changed 
the disease outcome, especially when initiated prior to the emergence of symptoms $(34,35)$. Our findings indicate that the utilization rate of novel and innovative treatments for SMA management is low in Saudi Arabia (more than 50\% of the respondents reported never prescribing nusinersen to their patients). However, most SMA patients who were prescribed nusinersen are taking it. In contrast, nearly all of the respondents did not prescribe onasemnogene abeparvovec, and no patient was started on it because this drug is not yet approved by the Saudi FDA. Our findings also highlight the significant transformation in SMA management in Saudi Arabia because a sizable minority of SMA patients have already started taking nusinersen, which was not available just a few years ago (27). Not surprisingly, two-thirds of the respondents said that only supportive care is available for their patients, and one-third used palliative care, do-not-resuscitate, and no endotracheal intubation, which is in accordance with international consensus guidelines $(15,29)$.

Onasemnogene abeparvovec for SMA treatment is widely accepted. Hoy et al. (36) reported the milestones of onasemnogene abeparvovec development in Europe and the United States. Onasemnogene abeparvovec is the first gene therapy to be approved for SMA management in children $<2$ years old (36). Therefore, there is a high preference for and acceptance of onasemnogene abeparvovec among neurologists in Europe and the United States (36). However, onasemnogene abeparvovec is the most expensive drug in the world, making it unaffordable for most healthcare institutions (36). This was clearly indicated by the majority of the respondents, who reported that the high acquisition cost of onasemnogene abeparvovec is the most daunting obstacle to using this novel treatment for their SMA patients and requires Ministry of Health approval. However, early economic reports have indicated better incremental cost-effectiveness ratios (ICERs) of onasemnogene abeparvovec compared to nusinersen despite the significantly higher cost of onasemnogene abeparvovec (37), probably because onasemnogene abeparvovec is administered only once in a lifetime compared to nusinersen, which must be administered regularly (37). Another obstacle is related to the logistics: $8.3 \%$ of the respondents said that their hospitals are prepared to handle gene therapy, which is consistent with the literature (38).

With regard to obstacles to the use of gene therapy, $73.9 \%$ of our respondents said that the major obstacle is the high cost, followed by a lack of expertise in using gene therapy, hospital logistical, and regulatory considerations. However, according to "SMA Therapies: ICER Grounds the Price to Value Conversation in Facts (37), the ICER quality-adjusted life-year (QALY) costeffective model for treating SMA found higher gains in QALY and life-years gained for onasemnogene abeparvovec compared to nusinersen.

Although $80 \%$ of our respondents had low to moderate knowledge of gene therapy for SMA, they said that they would recommend it. More than $50 \%$ of our respondents recommended onasemnogene abeparvovec because of its efficacy. In addition, $48.6 \%$ of them said that they would prescribe it for children $<6$ months old, while $78.3 \%$ said that they would prescribe it for SMA1. These data are similar to the healthcare providers' acceptance of other gene therapy modalities.

Al-Zaidy et al. (39) reported that onasemnogene abeparvovec is a promising drug and can achieve early treatment success in young infants with SMA.

To aid the rational use of onasemnogene abeparvovec for the treatment of SMA, a group of European neuromuscular experts published a consensus paper covering qualification, patient selection, safety considerations, and long-term monitoring. In addition, it is important that only qualified neurologists use gene therapy in expert centers (40).

This study had a few limitations. First, the number of pediatric neurologists in Saudi Arabia who are specialized in SMA management is limited. In 2017, the estimated total pediatric neurologist in Saudi Arabia was 75, with a ratio of 1.06 neurologists per 100,000 children (41). Therefore, the SMA management scope in Saudi Arabia might be shared with other specialties, which were not included in this study. Second, like all self-reported studies, the validity of outcomes depended on the respondents' honesty and subjective opinions. Third, involving trainees/residents may have affected some of the responses to questions especially when it come to the obstacles and care of patients with SMA. Finally, the study used convenience sampling in one setting, limiting the generalizability of the findings.

\section{CONCLUSION}

There is broad acceptance for different, novel, and innovative treatment options, including gene therapy, for SMA. Therefore, the entry of such novel, innovative, and high-cost treatments should be through an outcome-based agreement until the longterm follow-up data confirm real-world effectiveness. In parallel, the physicians' knowledge of these medications should be enhanced. Furthermore, decision-makers in the healthcare sector should consider our findings to facilitate SMA management.

\section{DATA AVAILABILITY STATEMENT}

The raw data supporting the conclusions of this article will be made available by the authors, without undue reservation.

\section{ETHICS STATEMENT}

The study was approved by the institutional review board of the College of Medicine, King Saud University (E18-3539). All information about the participating neurologists was kept confidential. The patients/participants provided their written informed consent to participate in this study.

\section{AUTHOR CONTRIBUTIONS}

All authors listed have made a substantial, direct and intellectual contribution to the work, and approved it for publication. 


\section{FUNDING}

This work was supported by the College of Medicine Research center, Deanship of Scientific Research, King Saud University, Riyadh, Saudi Arabia.

\section{REFERENCES}

1. Wirth B, Barkats M, Martinat C, Sendtner M, Gillingwater TH. Moving towards treatments for spinal muscular atrophy: hopes and limits. Expert Opin Emerg Drugs. (2015) 20:353-6. doi: 10.1517/14728214.2015.1041375

2. Faravelli I, Nizzardo M, Comi GP, Corti S. Spinal muscular atrophy-recent therapeutic advances for an old challenge. Nat Rev Neurol. (2015) 11:3519. doi: 10.1038/nrneurol.2015.77

3. Singh NN, Howell MD, Androphy EJ, Singh RN. How the discovery of ISS-N1 led to the first medical therapy for spinal muscular atrophy. Gene Ther. (2017) 24:520-6. doi: 10.1038/gt.2017.34

4. Prior TW, Leach ME, Finanger E. Spinal muscular atrophy. In: Adam MP, Ardinger HH, Pagon RA, Wallace SE, Bean LJH, Mirzaa G, et al. GeneReviews. Seattle, WA: University of Washington (2000). Available online at: https://www.zolgensma.com/familyvideos?gclid=Cj0KCQjw3duCBhCAARIsAJeFyPUI5wLrlTj1BcivGgmrZWUSIgMdSG2CFVWVdokkGabv011Xpf5d6caArDWEALw_ wcB (accessed July 24, 2020).

5. Mostacciuolo ML, Danieli GA, Trevisan C, Müller E, Angelini C. Epidemiology of spinal muscular atrophies in a sample of the Italian population. Neuroepidemiology. (1992) 11:34-8. doi: 10.1159/000110905

6. Sugarman EA, Nagan N, Zhu H, Akmaev VR, Zhou Z, Rohlfs EM, et al. Panethnic carrier screening and prenatal diagnosis for spinal muscular atrophy: clinical laboratory analysis of $>72,400$ specimens. Eur J Hum Genet. (2012) 20:27-32. doi: 10.1038/ejhg.2011.134

7. Pearn J. Incidence, prevalence, and gene frequency studies of chronic childhood spinal muscular atrophy. J Med Genet. (1978) 15:409-13. doi: 10.1136/jmg.15.6.409

8. Parente V, Corti S. Advances in spinal muscular atrophy therapeutics. Ther Adv Neurol Disord. (2018) 11:1756285618754501. doi: 10.1177/1756285618754501

9. Meyer K, Ferraiuolo L, Schmelzer L, Braun L, McGovern V, Likhite S, et al. Improving single injection CSF delivery of AAV9-mediated gene therapy for SMA: a dose-response study in mice and nonhuman primates. Mol Ther. (2015) 23:477-87. doi: 10.1038/mt.2014.210

10. Groen EJN, Talbot K, Gillingwater TH. Advances in therapy for spinal muscular atrophy: promises and challenges. Nature Rev Neurol. (2018) 14:214-24. doi: 10.1038/nrneurol.2018.4

11. Garber K. Big win possible for ionis/biogen antisense drug in muscular atrophy. Nat Biotechnol. (2016) 34:1002-3. doi: 10.1038/nbt1016-1002

12. Deverman BE, Ravina BM, Bankiewicz KS, Paul SM, Sah DWY. Gene therapy for neurological disorders: progress and prospects. Nat Rev Drug Discov. (2018) 17:641-59. doi: 10.1038/nrd.2018.110

13. Farrar MA, Park SB, Vucic S, Carey KA, Turner BJ, Gillingwater TH, et al. Emerging therapies and challenges in spinal muscular atrophy. Ann Neurol. (2017) 81:355-68. doi: 10.1002/ana.24864

14. Oliván S, Calvo AC, Rando A, Herrando-Grabulosa M, Manzano R, Zaragoza $\mathrm{P}$, et al. Neuroprotective effect of non-viral gene therapy treatment based on tetanus toxin C-fragment in a severe mouse model of spinal muscular atrophy. Front Mol Neurosci. (2016) 9:76. doi: 10.3389/fnmol.2016.00076

15. Wang CH, Finkel RS, Bertini ES, Schroth M, Simonds A, Wong B, et al. Consensus statement for standard of care in spinal muscular atrophy. J Child Neurol. (2007) 22:1027-49. doi: 10.1177/0883073807305788

16. Arnold WD, Kassar D, Kissel JT. Spinal muscular atrophy: diagnosis and management in a new therapeutic era. Muscle Nerve. (2015) 51:15767. doi: $10.1002 /$ mus. 24497

17. Darras BT. Spinal muscular atrophies. Pediatr Clin North Am. (2015) 62:74366. doi: 10.1016/j.pcl.2015.03.010

\section{ACKNOWLEDGMENTS}

The authors thank the Deanship of Scientific Research and RSSU at King Saud University for their technical support. The authors thank the Saudi Pediatric Neurology Society for their support.

18. Finkel RS, Mercuri E, Meyer OH, Simonds AK, Schroth MK, Graham RJ, et al. Diagnosis and management of spinal muscular atrophy: part 2: pulmonary and acute care; medications, supplements and immunizations; other organ systems; and ethics. Neuromuscul Disord. (2018) 28:197207. doi: 10.1016/j.nmd.2017.11.004

19. U.S. Food \& Drug Administration. FDA Approves First Drug for Spinal Muscular Atrophy. Available online at: www.fda.gov/newsevents/newsroom/pressannouncements/ucm534611.htm (accessed July 24, 2020).

20. Rüger J, Ioannou S, Castanotto D, Stein CA. Oligonucleotides to the (gene) rescue: FDA approvals 2017-2019. Trends Pharmacol Sci. (2020) 41:2741. doi: 10.1016/j.tips.2019.10.009

21. FDA Approves Innovative Gene Therapy to Treat Pediatric Patients With Spinal Muscular Atrophy, a Rare Disease and Leading Genetic Cause of Infant Mortality. Available online at: https://www.fda.gov/news- events/pressannouncements/fda-approves-innovative-gene-therapy-treat-pediatricpatients-spinal-muscular-atrophy-rare-disease (accessed July 24, 2020).

22. European Medicines Agency. Zolgensma. Available online at: https:// www.ema.europa.eu/en/medicines/human/EPAR/zolgensma (accessed July 24, 2020)

23. FDA Approves Oral Treatment for Spinal Muscular Atrophy. Available online at: https://www.fda.gov/news-events/press-announcements/fdaapproves-oral-treatment-spinal-muscular-atrophy\#:\$sim\$:text=The\%20U. S.\%20Food\%20and\%20Drug,approved $\% 20$ to\%20treat $\% 20$ this $\% 20$ disease (accessed July 24, 2020).

24. Ratni H, Karp GM, Weetall M, Naryshkin NA, Paushkin SV, Chen KS, et al. Specific correction of alternative survival motor neuron 2 splicing by small molecules: discovery of a potential novel medicine to treat spinal muscular atrophy. J Med Chem. (2016) 59:6086-100. doi: 10.1021/acs.jmedchem.6b00459

25. Ratni H, Ebeling M, Baird J, Bendels S, Bylund J, Chen KS, et al. Discovery of risdiplam, a selective survival of motor neuron-2 (SMN2) gene splicing modifier for the treatment of spinal muscular atrophy (SMA). J Med Chem. (2018) 61:6501-17. doi: 10.1021/acs.jmedchem.8b00741

26. Simoens S, Huys I. Market access of spinraza (nusinersen) for spinal muscular atrophy: intellectual property rights, pricing, value and coverage considerations. Gene Ther. (2017) 24:539-41. doi: 10.1038/gt.2017.79

27. Bashiri FA, Idris HA, Al-Sohime FM, Temsah MH, Alhasan KA. Effect of new modalities of treatment on physicians management plan for patients with spinal muscular atrophy. Neurosciences. (2019) 24:1621. doi: 10.17712/nsj.2019.1.20180321

28. Benson RC, Hardy KA, Gildengorin G, Hsia D. International survey of physician recommendation for tracheostomy for spinal muscular atrophy type I. Pediatr Pulmonol. (2012) 47:606-11. doi: 10.1002/ppul.21617

29. Wang CH, Bonnemann CG, Rutkowski A, Sejersen T, Bellini J, Battista V, et al. Consensus statement on standard of care for congenital muscular dystrophies. J Child Neurol. (2010) 25:1559-81. doi: 10.1177/08830738103 81924

30. Van Alstyne M, Pellizzoni L. Advances in modeling and treating spinal muscular atrophy. Curr Opin Neurol. (2016) 29:549-56. doi: 10.1097/WCO.0000000000000368

31. Day JW, Chiriboga CA, Crawford TO, Darras BT, Finkel RS, Connolly AM, et al. Onasemnogene abeparvovec-xioi gene-replacement therapy for spinal muscular atrophy type 1 (SMA1): Phase 3 US study (STR1VE) update 1828. Neurol. (2020) 94 (15 Suppl):1828.

32. Baranello G, Servais L, Day JW, Deconinck N, Mercuri E, Klein A, et al. FIREFISH part 1: 1-year results on motor function in babies with type 1 SMA (S25.003). Neurol. (2019) 92 (15 Suppl):S25. 
33. Mercuri E, Barisic N, Boespflug-Tanguy O, Deconinck N, Kostera-Pruszczyk A, Masson R, et al. SUNFISH part 2: efficacy and safety of risdiplam (RG7916) in patients with type 2 or non-ambulant type 3 spinal muscular atrophy (SMA) 1260. Neurology. (2020) 94 (15 Supple):1260.

34. De Vivo DC, Bertini E, Swoboda KJ, Hwu WL, Crawford TO, Finkel RS, et al. Nusinersen initiated in infants during the presymptomatic stage of spinal muscular atrophy: interim efficacy and safety results from the phase 2 NURTURE study. Neuromusc Disord. (2019) 29:84256. doi: 10.1016/j.nmd.2019.09.007

35. Dangouloff T, Servais L. Clinical evidence supporting early treatment of patients with spinal muscular atrophy: current perspectives. Ther Clin Risk Manag. (2019) 15:1153-61. doi: 10.2147/TCRM.S172291

36. Hoy SM. Onasemnogene abeparvovec: first global approval. Drugs. (2019) 79:1255-62. doi: 10.1007/s40265-019-01162-5

37. Malone DC, Dean R, Arjunji R, Jensen I, Cyr P, Miller B, et al. Cost-effectiveness analysis of using onasemnogene abeparvocec (AVXS-101) in spinal muscular atrophy type 1 patients. J Mark Access Health Policy. (2019) 7:1601484. doi: 10.1080/20016689.2019.1 601484

38. Starner CI, Gleason PP. Spinal Muscular atrophy therapies: ICER grounds the price to value conversation in facts. J Manag Care Spec Pharm. (2019) 25:1306-8. doi: 10.18553/jmcp.2019.25.12.1306

39. Al-Zaidy SA, Mendell JR. From clinical trials to clinical practice: practical considerations for gene replacement therapy in SMA type
1. Pediatr Neurol. (2019) 100:3-11. doi: 10.1016/j.pediatrneurol.2019. 06.007

40. Kirschner J, Butoianu N, Goemans N, Haberlova J, Kostera-Pruszczyk A, Mercuri E, et al. European ad-hoc consensus statement on gene replacement therapy for spinal muscular atrophy. Eur J Paediatr Neurol. (2020) 28:3843. doi: 10.1016/j.ejpn.2020.07.001

41. Al-Nahdi B, Ashgar M, Domyati M, Alwadei A, Albaradie R, Jan M. Pediatric neurology workforce in Saudi Arabia. J Pediatr Neurol. (2017) 15:16670. doi: $10.1055 /$ s-0037-1598105

Conflict of Interest: Medical writing services were hired by Novartis Gene Therapies that took no part in the analysis or interpretation of the data.

The authors declare that the research was conducted in the absence of any commercial or financial relationships that could be construed as a potential conflict of interest.

Copyright (C) 2021 Bashiri, Temsah, Hundallah, Alsohime and AlRuthia. This is an open-access article distributed under the terms of the Creative Commons Attribution License (CC BY). The use, distribution or reproduction in other forums is permitted, provided the original author(s) and the copyright owner(s) are credited and that the original publication in this journal is cited, in accordance with accepted academic practice. No use, distribution or reproduction is permitted which does not comply with these terms. 